\title{
Identificação de Fungos em Sementes de Dimorphandra mollis e Efeito de Diferentes Tratamentos
}

\author{
Iure Giuliano ${ }^{1}$, Tatianne Gizelle M. Silva ${ }^{2}$, Reginaldo Napoleão ${ }^{3}$, Antonio H. Gutiérrez ${ }^{4}$ \\ \& Carolina S. Siqueira ${ }^{2}$
}

${ }^{1}$ UFMG - NCA, Cx. Postal 135, CEP 39404-006, Montes Claros, MG; ${ }^{2}$ Unimontes, campus Darcy Ribeiro, 39401-089, Montes Claros, MG; ${ }^{3}$ Fafeid, Rua da Glória, 187, Centro, CEP 39100-000, Diamantina, MG, e-mail: napoleao@fafeid.edu.br, ${ }^{4}$ Universidadade Federal do Pará, Departamento de Patologia, Centro de Ciências Biológicas, Campus Universitário do Guamá, Rua Augusto Corrêa 01, Cx. Postal 479, Belém, PA, CEP 66071-110

(Aceito para publicação em 26/02/2005)

Autor para correspondência: Reginaldo Napoleão

\begin{abstract}
Fungus identification on Dimorphandra mollis seeds and the effect of different treatments

The fungus Absidia corymbifera, Curvularia pallescens, Aspergillus niger, Arpergillus sp., and an unidentified fungus were found on Dimorphandra mollis seeds. Captan + mancozeb were the best treatment to control these fungi although their use did not increase seed germination, but rather, reduced death after germination.
\end{abstract}

A fava-d'anta (Dimorphandra mollis Benth), espécie nativa do Cerrado Brasileiro, tem uso medicinal (Bezerra et al. Fitoterapia 73:428. 2002) e alto potencial econômico. Sementes de fava d'anta são portadoras de microrganismos que podem interferir na germinação e causar a morte das mesmas. Além do baixo índice de germinação, que ocorre naturalmente (Hermansen et al. Seed Science and Technology. 28:567. 2000) nota-se uma taxa elevada de sementes contaminadas, que morrem logo após a germinação.

Este trabalho teve como objetivos identificar os fungos presentes nas sementes de fava d'anta e avaliar a eficiência de produtos no controle desses microrganismos e na germinação das sementes. O ensaio foi delineado em blocos ao acaso, com quatro tratamentos e cinco repetições contendo 100 sementes cada. As sementes foram escarificadas mecanicamente com esmeril (Harmansen et al. Seed Science and Techonology. 28:581. 2000), desinfestadas com solução de hipoclorito de sódio a $2 \%$, tratadas e colocadas para germinar em de areia esterilizada. Os tratamentos consistiram em mergulhar as sementes por 10 min nas seguintes soluções: Benomyl (100 g/l), Mancozeb (50 g/l) + Captam (50 g/l), extrato puro de Neem (Azadirachta indica A. Juss) (Hirose et al. Brazilian Archives of Biology and technology. 44:419423. 2001) e, água. Foi avaliada a porcentagem de sementes germinadas. Das sementes germinadas, determinou-se o percentual de contaminação e morte. Os dados obtidos foram transformados em $\sqrt{x+0,5}$ para a análise estatística. Para identificação dos fungos e determinação da porcentagem de contaminação, foi utilizado o método do papel de filtro com 400 sementes escarificadas e desinfestadas.

Os fungos encontrados nas semente foram: Absidia corymbifera (Cohn) Sacc \& Trotter (1,0\%), Curvularia pallescens Boedjin (3,0\%), Arpergillus niger van Tieghem (1,8\%), Aspergillus sp. (2,0\%), e uma outra espécie, ainda não identificada, caracterizada por micélio branco estéril $(8,0 \%)$. Os mesmos fungos foram isolados das sementes colocadas em areia. O fungo A. corymbifera é um patógeno encontrado em amêndoas de cajueiro (Anacardium ocidentale L.) (Freire \& Barguil. Embrapa Comunicado Técnico 64. 2001), e A. niger em sementes de amendoim (Arachis hypogaeae L.), causando podridão do colo da planta (Ahmed \& Reddy. Icrisat, Índia Information Bulletin $n^{0} 34.1993$ ). Dentre os tratamentos utilizados, não foi observada diferença estatística significativa $(\mathrm{p}>0,05)$ para a porcentagem de germinação $(50,2 \%)$, mas observou-se diferença $(p<0,05)$ para a porcentagem de contaminação e morte das sementes germinadas. Todas as sementes germinadas e contaminadas morreram. O melhor tratamento no controle dos fungos foi captan + mancozeb, resultando em $0,4 \%$ de contaminação das sementes germinadas, levando-as à morte, enquanto nos demais tratamentos esse percentual variou de $14,3 \%$ a $56,8 \%$.

O uso de captan+mancozeb mostrou-se promissor no tratamento de sementes de $D$. mollis. Em relação à testemunha, ele reduziu em 142 vezes o percentual de sementes contaminadas e mortas após a germinação. 